\title{
An online formative assessment tool to prepare students for summative assessment in physiology
}

\author{
S Kerr, ${ }^{1} \mathrm{PhD}$; D Muller, ${ }^{1} \mathrm{PhD}$; W McKinon, ${ }^{1} \mathrm{PhD}$; P Mc Inerney, ${ }^{2} \mathrm{PhD}$ \\ ${ }^{1}$ School of Physiology, Faculty of Health Sciences, University of the Witwatersrand, Johannesburg, South Africa \\ ${ }^{2}$ Centre for Health Science Education, Faculty of Health Sciences, University of the Witwatersrand, Johannesburg, South Africa
}

Corresponding author: S Kerr (samantha.kerr@wits.ac.za)

\begin{abstract}
Background. The didactic approach to teaching physiology in our university has traditionally included the delivery of lectures to large groups, illustrating concepts and referencing recommended textbooks. Importantly, at undergraduate level, our assessments demand a level of application of physiological mechanisms to recognised pathophysiological conditions.

Objective. To bridge the gap between lectured material and the application of physiological concepts to pathophysiological conditions, we developed a technological tool approach that augments traditional teaching.

Methods. Our e-learning initiative, eQuip, is a custom-built e-learning platform specifically created to align question types included in the program to be similar to those used in current assessments. We describe our formative e-learning system and present preliminary results after the first year of introduction, reporting on the performances and perceptions of 2nd-year physiology students.

Results. Students who made use of eQuip for at least three of the teaching blocks achieved significantly better results than those who did not use the program $(p=0.0032)$. Questionnaire feedback was positive with regard to the administration processes and usefulness of eQuip. Students reported particularly liking the ease of access to information; however, $<60 \%$ of them felt that eQuip motivated them to learn.

Conclusion. These results are consistent with the literature, which shows that students who made use of an online formative assessment tool performed better in summative assessment tasks. Despite the improved performance of students, the questionnaire results showed that student motives for using online learning tools indicated that they lack self-directed learning skills and seek easy access to information.
\end{abstract}

Afr J Health Professions Educ 2016;8(1):72-76. DOI:10.7196/AJHPE.2016.v8i1.581

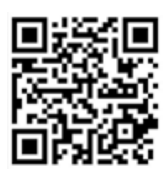

The traditional approach to teaching physiology at our university has been the delivery of a didactic lecture by an expert standing in front of the class. The lecture format usually involves the use of PowerPoint slides or chalk and a blackboard to illustrate concepts. After the lecture, students are referred to a recommended non-South African textbook. ${ }^{[1]}$ Frequently, especially in large medical student classes, the lecturer may be unavailable on a one-to-one basis for follow-up tuition. Therefore, students may find themselves in a situation where misconceptions or poorly received concepts are not easily addressed and corrected. These students may subsequently ignore or discard the information and consequently perform poorly in assessments. They could therefore overlook the relevance of the knowledge, which in the context of medical disciplines, may have an effect on their careers and ability to treat their patients. Moreover, diligent students who seek to further investigate a concept, frequently do not know where to find the relevant information in their textbook, the library or even on the internet.

A number of different emerging factors have made the challenges of effective teaching of healthcare professionals even more difficult in the local South African (SA) context. These include a changing school education system where disparate pedagogical approaches have been implemented over the last decade; ${ }^{[2]}$ a changing patient population, with the emergence of previously neglected or unknown diseases; ${ }^{[3]}$ and a lack of available resources, making clinical insight even more important as the primary tool available to healthcare workers. Consequently, long-established didactic approaches to the teaching of physiology may no longer fully meet the needs of current students or fulfil the demands for effective training of healthcare professionals. The promotion of active and self-directed learning, which may be defined as the process in which students identify their learning niches and strengths and take the initiative to fulfil their learning requirements, may be achieved through an e-learning system ${ }^{[1]}$ that may prove to be a useful aid in supplementing the learning of students. A review article by Michael, ${ }^{[4]}$ focusing on physiological education, highlights the evidence that active learning approaches to teaching are more effective than passive methods. The evidence suggests that active learning promotes meaningful learning and performance is improved if these methods are employed. Online learning tools, which promote active learning by students, provide a supplemental resource through which students may engage the use of assessment with feedback, which potentially allows for tutoring that may not otherwise have been available.

There is evidence to suggest that e-learning tools are an effective method of providing additional teaching aids to students and also improve outcomes on summative test assessments. ${ }^{\left[{ }^{[}\right]}$Formative assessment provides immediate feedback to students and promotes student learning, whereas summative assessment is an evaluation of student learning. ${ }^{[6]}$ e-learning systems are largely formative tools employed to assist students in summative assessment tasks. ${ }^{[5]}$ According to Velan et al., ${ }^{[7]}$ the advantages of online formative assessments include 'immediacy of feedback, flexibility in time and place of undertaking the assessment; feedback can provide links to learning resources, thereby providing motivation to study, opportunity for repetition, and interactivity' ${ }^{[7]}$

Therefore, in our school, we have decided to embrace the technological approach to assist in meeting the needs of current learners. The use of computerised learning methods not only appears to lend themselves to the tech-savvy nature of the new generation of learners, but also allows students 
to learn physiological concepts at their own pace, revisit misunderstood concepts and shift their focus to where they may need the most conceptual support.

In this article we assess the results of implementing our new e-learning system, designed as a formative teaching tool with the objective to provide factual knowledge and immediate results of formative assessments to students, including detailed explanations of the correct physiology after each assessment. The system has been designed to provide a student with experience in answering test questions relevant to their discipline, while explaining basic physiological concepts. Furthermore, our system is designed to provide SA students with knowledge applicable and relevant to the local population rather than information more relevant to North American or European populations, which are conventionally used. In this study, our objective was to assess the performance of students (summative assessment) after the introduction of an e-learning tool as a supplemental tool for learning and the subjective reactions of students to using such a tool.

\section{Background \\ Students}

The School of Physiology, University of the Witwatersrand, Johannesburg, SA teaches courses in physiology and medical biochemistry as compulsory components of 2nd-year undergraduate curricula in a range of different medical disciplines. These include pharmacy, physiotherapy, occupational therapy, nursing, dentistry, medicine, health sciences and biomedical engineering. The physiology course is divided into four 8 - 10-week blocks and is delivered through a series of lectures ( 5 hours per week), tutorials ( 3 hours per week) and practical laboratory skill sessions (3 hours per week). All lectures and tutorials are taught by academic staff members and practical sessions are demonstrated by trained postgraduate students under the guidance of academic staff members. The therapeutic health science course is taught to students studying pharmacy, physiotherapy, occupational therapy, nursing and dentistry as one class $(N=220)$. Students write a summative test at the end of each of the four teaching blocks (based on the work covered in that quarter) and a final assessment at the end of the year (based on the course content taught throughout the year). The therapeutic health science course material includes the following: Test 1: blood, body fluids, immunology, metabolism, autonomic nervous system and excitable tissue; Test 2: metabolism, central nervous system and temperature regulation; Test 3: cardiovascular system, respiration, kidney, acid-base and gastro-intestinal system; and Test 4: liver, endocrine and exercise.

\section{eQuip}

In addition to lectures, tutorials and laboratory sessions, which were already in place, an e-learning initiative was introduced as a tool to supplement students' understanding of physiology and the method of assessment. eQuip (eQuestions for Understanding Integrated Physiology) is a custom-built e-learning platform to suit the specific needs of the school (developed by the school in collaboration with coding expertise supplied by an external information technology firm (Simnat Technology Pty Ltd, Johannesburg). The framework for the platform was based on the X-type multiple-choice questions (MCQs) used in our current assessments, developed by Mitchell. ${ }^{[8]}$ In our assessment protocol and eQuip program each MCQ statement has five corresponding responses, where each response must be answered as true or false. Each MCQ therefore contains five questions or statements that require an answer. In the eQuip program, once a question has been answered (true or false selected), the student is given feedback on whether they were correct or incorrect. Additionally, an extensive explanation as to why the statement was true or false is presented to the student. Model answers have been researched and validated under the supervision of subject expert academic staff to align the model answers with current course content and objectives. Furthermore, images and explanations detailing the underlying mechanisms that explain the reasons for statements being correct or incorrect have been sourced, designed and included, enabling the students to visualise the rationale behind each statement. Selected responses also have links to approved internal library e-references or external sites (such as YouTube videos) that further clarify concepts. Therefore, eQuip was specifically designed and created to align the question types included in the program to be similar to those used in our current assessment protocols, providing experience in answering X-type MCQs and offering immediate feedback. The eQuip program draws on Kolb's experiential learning cycle, as it offers students the opportunity for concrete experience and active experimentation; the immediate feedback provides them with an opportunity for reflective observation and abstract conceptualisation. ${ }^{[9]}$

The home page of eQuip is divided into 16 topics, reflecting the structure of the course topics taught throughout the year. There are approximately 500 MCQs with model answers captured in the system. A unique feature of the system is that many of the questions included are based on diseases or problems prevalent in patients seen in African hospitals. Thus, at an early point in their medical career, students are being exposed to problem-solving around problems and diseases such as malaria, HIV and kwashiorkor.

\section{Methods \\ Study design}

At the start of the academic year all the students who registered for therapeutic health sciences disciplines were given a brief orientation session to familiarise them with eQuip and encourage them to use the platform. Participation was voluntary and no extra credit incentives were offered to encourage use of the program. Students accessed eQuip using their personal student identification username and password. No time limitations were placed on answering the questions, as it was felt that this was a learning platform and students could take as much time as required to interact with the system. Because of internet security issues, the site was only accessible from computer laboratories at the university and students could not access the platform off campus.

\section{Questionnaire}

A paper-based questionnaire to obtain feedback about eQuip was administered to the students in the final lecture of the year as part of the department-approved course evaluation. This formed a convenience sample, as not the entire class was present. The students were asked to volunteer to complete the questionnaire and could elect to complete it anonymously. It was made clear to them that there was no obligation to complete the questionnaire and they would not be disadvantaged should they choose not to participate. The questionnaire administrators and e-learning team played no role in the summative assessment process. Using a 5-point Likert scale, eQuip-specific questions were answered on ease of access, frequency of usage, relevance of material and whether students were satisfied and would recommend the program. Furthermore, based on the questionnaire developed by Seluakumaran et al., ${ }^{[10]}$ students were asked what the most useful features were. 


\section{Outcomes}

Student logins to eQuip were tracked throughout the year to determine the percentage use of the program and the number of teaching blocks each student made use of. Fisher's exact $2 \times 2$ contingency tables were used to assess the relationship between students who passed and those who failed (50\% cut-off) and their eQuip use per teaching block. Year-end grades (average of the results of the test at the end of each of the academic teaching blocks) were compared (using analysis of variance (ANOVA) with a Tukey's posthoc test) according to the number of teaching blocks where the student had made use of eQuip.

\section{Results \\ Participants}

The mean (SD) percentage of students who used eQuip throughout the year was 67 (6.9)\%. A statistically significant percentage of students who passed used eQuip (62\%), compared with only $25 \%$ of those who failed $(p=0.0036)$. A significantly greater proportion of students who

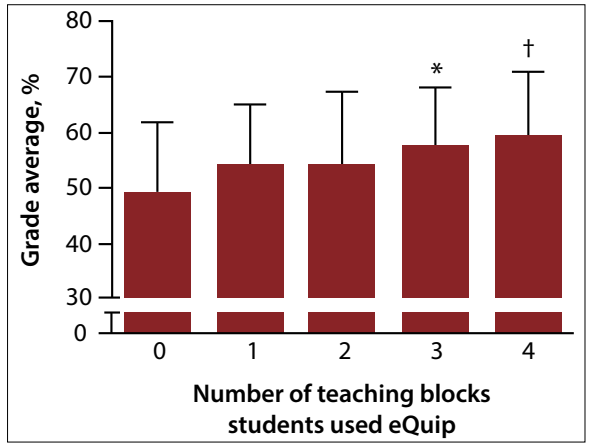

Fig. 1. Comparison between physiology year-end grade averages for therapeutic health science students based on the number of blocks for which the students used the e-learning tool eQuip (ANOVA, $\mathrm{p}=0.0032$; Tukey's posthoc test, three blocks used v. eQuip not used $\left({ }^{*} \mathrm{p}<0.05\right)$, four blocks used v. eQuip not used $\left.\left({ }^{\dagger} \mathrm{p}<0.01\right)\right)$. used eQuip in all four teaching blocks passed compared with those not making use of the program ( $p=0.0006$; Table 1$)$.

Students using eQuip for at least three academic blocks achieved significantly better year-end results than those who did not make use of the program (Fig. 1). Students were normally distributed in terms of grades achieved in the group using eQuip and those not using the program.

\section{Questionnaire results}

Completed questionnaires were received from $66 \%(n=146)$ of the class, and $92 \%$ of respondents stated that they had made use of eQuip at least once (Table 2). The students indicated that they made use of the e-learning tool most frequently immediately before tests.

Although 146 questionnaires were collected from the class, some of the respondents elected not to answer all the statements. Accordingly, each of the statements was calculated as a percentage of the responses for that statement (Tables 2 and 3). In each case $\leq 20$ students failed to provide an answer to any question posed. Overall, feedback from the class was positive with regard to the registration process, access, ease of use, satisfaction and relevance of material on eQuip. Students found the MCQ model answers and images particularly useful, but provided mixed reactions about the links to other sites.

\section{Discussion}

Students who made use of eQuip achieved significantly better results in their summative tests than those who did not use the program, suggesting that the introduction of the online tool facilitated the learning process for students.

This study is congruent with numerous studies focusing on medical education, which have also demonstrated that students who participate in formative online assessments and use supplementary tools performed better in summative tests and assessments. ${ }^{[5-7,70-13]}$ The significant differences in year-end results between the students who consistently used eQuip and those who did not may be a reflection of the higher percentage of use of the program and that students received greater benefit from the system. Kibble ${ }^{[12]}$ noted that students are less likely to participate in formative assessment tasks if participation is voluntary. Although the average use of the program throughout the year was $>60 \%, \sim 13 \%$ of the class reported that they had either not heard or made use of it, in the latter case primarily because access was restricted to on-campus use. Therefore, it is worthwhile noting that frequent promotion and accessibility are key features in the success of implementing an e-learning program.

Historically, students have struggled in the first tests in our 2nd-year physiology course, as they are introduced to a new question format and a more challenging course than they experienced during their 1st year of study. By modelling the question type included in the e-learning program on the assessment protocol, students were familiarised with the question format when using the online system before writing the test, which may have assisted them when writing the summative assessments. Familiarisation with the question format highlights one of the strengths of eQuip, which exposes students to the question type and expectations in answering styles, thus providing them with experience with the question type. Previous literature has shown formative assessments (such as our eQuip-based questions) to be most effective if they are similar to the summative assessments that they are supporting. ${ }^{[5,14]}$

Features of the eQuip system that we considered key to the successful implementation of our formative e-learning tool included the creation of a system that encouraged the learning process and provided timely and

Table 1. Students who passed or failed 2nd-year physiology according to the number of teaching blocks for which they used the e-learning program eQuip

\begin{tabular}{lll}
\hline $\begin{array}{l}\text { Number of teaching blocks students } \\
\text { used eQuip, } \boldsymbol{n}\end{array}$ & Students who passed, \% & Students who failed, \% \\
\hline 0 & 6 & 7 \\
1 & 5 & 4 \\
2 & 12 & 7 \\
3 & 15 & 5 \\
$4^{*}$ & 31 & 8 \\
${ }^{*} p=0.0064$ v. 0 (Fisher's exact test). & &
\end{tabular}

Table 2. Summary of student feedback with regard to the use of eQuip

\begin{tabular}{ll}
\hline Did you make use of eQuip? & Students, \% \\
\hline I looked at it once & 5 \\
I used it just before tests & 49 \\
I consistently used it & 38 \\
I knew about it but I never & 5 \\
used it & \\
$\begin{array}{l}\text { What is eQuip? I've never heard } \\
\text { about it or used it }\end{array}$ & 3
\end{tabular}


Table 3. Summary of therapeutic health science students (physiology) feedback with regard to eQuip, provided by a questionnaire using a condensed Likert scale

\begin{tabular}{|c|c|c|c|}
\hline \multirow[b]{2}{*}{ Student feedback } & \multicolumn{3}{|c|}{ Students, \% } \\
\hline & Agree & Neutral & Disagree \\
\hline The registration process for eQuip was easy & 87 & 9 & 4 \\
\hline eQuip was easy to access & 71 & 14 & 16 \\
\hline I was happy and satisfied to use eQuip & 91 & 5 & 4 \\
\hline eQuip was easy to navigate and use & 93 & 4 & 2 \\
\hline The material on eQuip was relevant and appropriate & 94 & 5 & 1 \\
\hline $\begin{array}{l}\text { eQuip helped me to further my understanding about the topic taught } \\
\text { in physiology }\end{array}$ & 90 & 7 & 2 \\
\hline $\begin{array}{l}\text { eQuip complemented traditional learning through lectures and } \\
\text { tutorials }\end{array}$ & 84 & 14 & 1 \\
\hline I recommend the School of Physiology to continue using eQuip & 96 & 1 & 3 \\
\hline I don't think I learnt much from eQuip & 5 & 13 & 82 \\
\hline I like reading notes/textbooks rather than using eQuip & 11 & 28 & 60 \\
\hline eQuip motivated me to learn & 61 & 31 & 8 \\
\hline \multicolumn{4}{|l|}{ The most useful features of eQuip } \\
\hline Model answers to each question & 97 & 3 & 0 \\
\hline The images & 84 & 12 & 4 \\
\hline That it allowed me to practise MCQs, but wasn't for marks & 92 & 7 & 1 \\
\hline Easy access to the model answers & 91 & 8 & 2 \\
\hline Links to other sites & 47 & 30 & 23 \\
\hline
\end{tabular}

informative feedback. Marden et al ${ }^{[15]}$ reported that formative learning tools were more useful when students were allowed multiple unsupervised and untimed attempts. Therefore, another strength of e-Quip is that it creates a non-intimidating environment for students to assess and re-assess their knowledge and practise questions. Furthermore, to facilitate student understanding and foster a student's sense of responsibility for their learning, it was seen as beneficial that our formative assessment provides informative and supportive feedback, rather than just a grade, and does so in a timely manner to optimise learning outcomes. ${ }^{[16,17]}$

We cannot definitively state that the higher results obtained by eQuip users compared with the results of those who did not use the program were because more conscientious students made use of the system and whether they would have obtained such results without the program. However, the distribution curves of the grades for students who used the system and those who did not indicate that there was an even distribution of strong and weak students. Two studies by Kibble et al. ${ }^{[11,13]}$ demonstrated that students were more likely to participate in formative assessment tasks if there were extra credit incentives. However, as noted by Kibble, increasing incentives to participate may result in a disconnect between the final grades and the amount of online participation. If incentives are offered, the motivation for using the program may not be the attainment of knowledge but rather to achieve the necessary grades.

In contrast to incentive-driven engagement with a formative assessment tool, voluntary participation in formative assessment tasks is more likely a reflection of self-directed learning. Our students had the freedom to access information from a reliable source at their convenience (albeit limited to on-campus access) and they could control the amount of in- and output that they obtained, essentially empowering them to take control of their learning. Self-directed learners are able to identify their own deficits and make amends. eQuip lends itself to this, as it allows students to work at their own pace and apply information. This is particularly useful in the local setting, as the majority of the class are second-language learners (not learning in their mother tongue).

Conversely, it is possible that the easy access to answers on eQuip may actually facilitate a lack of self-directed learning. The results from the questionnaire indicated that students were motivated to use eQuip, as the system provided them with easy access to model answers, which the students rated as particularly useful. It is possible that students viewed the system as a means to attaining the correct answers and not as a learning tool. Taradi et al. ${ }^{[18]}$ captured this idea by stating 'the real power of computers to improve education will only be realized when students actively use them as cognitive tools rather than passively perceive them as tutors or repositories of information'

The mixed student reaction to the additional resources supplied supports the notion that students may have used eQuip merely as an information repository. We expected that the additional resources would guide students to further their knowledge and correct misconceptions through their own learning process. However, $<50 \%$ of students agreed that the links to other sites were useful. We speculate that the students may have considered it too much effort to access the additional material or that this information was superfluous to the content provided by their lecturers. Further investigation into reasons why these resources were not utilised and which resources were used is required.

\section{Study limitations}

Results from our questionnaire survey found that students complained about access to the system being limited to computer laboratories on campus and felt that they would have used the program more often if they could have accessed it from their home environment, an issue which we have subsequently addressed and rectified. Additionally, technical difficulties with access to the system were resolved when students reported such issues. As access to the system is a fundamental requirement for compliance, the provision of technical assistance (in our case, by making the contact details of the system administrator available to students) is vital to its success. The study design could not control for potential confounding variables regarding the study population. We previously stated that the higher grades obtained by eQuip users could have been because the more conscientious students made use of the system and would, regardless, have obtained higher marks; this should be considered a limitation. Moreover, the motivating factors and likelihood to commit to learning in an online environment were not 
considered in this study, which is a potential limitation and requires further research.

\section{Conclusion}

The implementation of a physiological e-learning program was related to improved summative assessment performance in a cohort of undergraduate students; however, improvements are only evident with frequent use. These results are consistent with those in the literature, which recommend the use of active online learning tools to promote educational performance. Results from a questionnaire assessing the students' experiences suggested that the program was found to be a useful and relevant addition to our undergraduate physiology courses. Recommendations include further research into the additional resources the students are utilising and motivations behind committing to online learning tools. Moreover, encouraging students to frequently use the platform and take responsibility for their learning should further improve performance.

Acknowledgements. We would like to thank Prof. Elena Libhaber, University of the Witwatersrand, for her assistance with the statistical analysis.

\section{References}

1. Gorman PJ, Meier AH, Rawn C, Krummel TM. The future of medical education is no longer blood and guts, it is bits and bytes. Am J Surg 2000;180:353-356. [http://dx.doi.org/10.1016/S0002-9610(00)00514-6]
Aldridge JM, Laugksch RC, Fraser BJ. School-level environment and outcomes-based education in South Afric Learning Environments Research 2006;9(2):123-147. [http://dx.doi.org/10.1007/s10984-006-9009-5]

3. Etyang AO, Scott JAG. Medical causes of admissions to hospital among adults in Africa: A systematic review Glob Health Action 2013;6(1):1-14. [http://dx.doi.org/10.3402/gha.v6i0.19090]

4. Michael J. Where's the evidence that active learning works? Adv Physiol Educ 2006;30:159-167. [http://dx.do org/10.1152/advan.00053.2006]

5obson JL. The use of formative online quizzes to enhance class preparation and scores on summative exams. Adv Physiol Educ 2008;32:297-302. [http://dx.doi.org/10.1152/advan.90162.2008]

6. Olson BL, McDonald JL. Influence of online formative assessment upon student learning in biomedical science courses. J Dental Educ 2004;68:56-65.

7. Velan GM, Jones P, McNeil HP, Kumar RK. Integrated online formative assessments in the biomedical sciences for medical students: Benefits for learning. BMC Med Educ 2008:8:52. [http://dx.doi.org/10.1186/1472-6920-8-52] Mitchell G. Medical Physiology: Objectives and Multiple Choice Questio

8. Mitchell G. Metal Butterworths, 1986 T, ed. Understanding Medical Education. Evidence, Theory and Practice. London: Wiley Blackwell, 2014.

10. Seluakumaran $K$, Jusof FF, Ismail R, Husain R. Integrating an open-source course management system (Moodle) Seluakumaran K, Jusof FF, Ismail R, Husain R. Integrating an open-source course management system (Moodle)
into the teaching of first-year medical physiology course: A case study. Adv Physiol Educ 2011;35:369-377. [http://dx.doi.org/10.1152/advan.00008.2011]

11. Kibble $J$. Use of unsupervised online quizzes as formative assessment in a medical physiology course: Effects of incentives on student participation and performance. Adv Physiol Educ 2007;31:253-260. [http://dx.do org/10.1152/advan.00027.2007]

12. Kibble JD. Voluntary participation in online formative quizzes is a sensitive predicator of student success. Adv Physiol Educ 2011;35:95-96. [http://dx.doi.org/10.1152/advan.00053.2010]

13. Kibble JD, Johnson TR, Khalil, MK, et al. Insights gained from analysis of performance and participation in onlin formative assessment. Teach Learn Med 2011;23(2):125-129. [http://dx.doi.org/10.1080/10401334.2011.561687]

14. Rolfe I, McPherson J. Formative assessment: How am I doing? Lancet 1995;345:837-839. [http://dx.dol. org/10.1016/S0140-6736(95)92968-1]

15. Marden NY, Ulman LG, Wilson FS, Velan GM. Online feedback assessments in physiology: Effects on students' learning experiences and outcomes. Adv Physiol Educ 2013;37:192-200. [http://dx.doi.org/10.1152/ advan.00092.2012]

16. Gipps V. What is the role for ICT-based assessment in universities? Studies in Higher Education 2005;30(2):71180. [http://dx.doi.org/10.1152/advan.00092.2012]

17. Hattie J, Timperley H. The power of feedback. Rev Educ Res 2007;77(1):81-112. [http://dx.doi Hattie J, Timperley $H$. The
org/10.3102/003465430298487]

18. Taradi SK, Taradi M, Radić K, Pokrajac N. Blending problem-based learning with Web technology positively impacts students learning outcomes in acid-base physiology. Adv Physiol Educ 2005;29:35-39. [http://dx.dol org/10.1152/advan.00026.2004] 